\title{
Cluster Analysis of Urban Unit Employment based on SPSS
}

\author{
Yuqi Luo ${ }^{1}$, Shuang Zhou ${ }^{2}$ \\ ${ }^{1}$ Statistic Institute, Shanxi University of Finance and Economics, wucheng road, Taiyuan, China \\ ${ }^{2}$ Institute of Cultural Communication, Shanxi University of Finance and Economics, wucheng road, \\ Taiyuan, China
}

Keywords: Employment; Cluster analysis; SPSS

Abstract: In 1999, the state implemented the reform of university enrollment system, and China's higher education entered a period of rapid development, and all kinds of work of higher education made great progress. At the same time, with the number of college students increased sharply, the employment situation of college students is becoming increasingly serious. According to the data in the 2017 statistical yearbook, there are a total of 19 industries, and there is a significant difference in the number of employed people in different industries between different provinces, which is mainly due to the different economic development status and geographical location between different provinces, resulting in the difference in advantageous industries. In this paper, cluster analysis was conducted on the basis of the number of employed people in urban units by industry in 2016, and 31 provinces were divided into 4 categories. On this basis, common grounds and differential factors of various types were analyzed and feasible suggestions were proposed.

\section{Introduction}

In the context of China's economic industrial upgrading and supply-side structural reform, enterprises are faced with many challenges in the transformation and upgrading of old and new driving forces. The relatively small recruitment demand of enterprises for talents leads to a relatively severe employment situation. Meanwhile, the number of college graduates is increasing day by day. It is widely believed that those industries such as finance, IT and electronic information are difficult to find jobs, while seemingly non-technical industries such as agriculture and mining are underemployed and unpopular. In fact, we should not only use industry as the selection criteria, but also integrate the geographical location and development advantages of various cities. The number of people employed in the same industry varies greatly from city to city.

\section{Clustering analysis}

The following table is the data of employment number of urban units in some provinces at the end of 2016 in some industries in 2017 statistical yearbook. 
Table 1 The number of employed persons in urban units in some provinces (2016)

\begin{tabular}{lllllllll}
\hline Region & $\mathrm{A}$ & $\mathrm{B}$ & $\mathrm{C}$ & $\mathrm{D}$ & $\mathrm{E}$ & $\mathrm{F}$ & $\mathrm{G}$ & $\mathrm{H}$ \\
\hline Beijing & 3.7 & 4.5 & 86.9 & 9.1 & 45.9 & 78.4 & 58.2 & 29.4 \\
\hline Tianjin & 0.8 & 4.4 & 99.4 & 4.3 & 28.2 & 18.2 & 14.7 & 5.1 \\
\hline Hebei & 3.9 & 22.8 & 136.3 & 18.8 & 81.8 & 26.9 & 28.7 & 5.4 \\
\hline Shanxi & 1.7 & 91.1 & 63.8 & 12.5 & 29.4 & 17.1 & 23.4 & 3.9 \\
\hline $\begin{array}{l}\text { Inner } \\
\text { Mongolia }\end{array}$ & 22.9 & 16.6 & 43.9 & 14.5 & 18.9 & 8.9 & 22.8 & 3.7 \\
\hline Liaoning & 22.7 & 24.7 & 131.7 & 14.7 & 64.6 & 22.6 & 35.2 & 6.2 \\
\hline Jilin & 12.5 & 13.1 & 81.9 & 12.3 & 27.3 & 11.6 & 16.1 & 2.8 \\
\hline Heilongjiang & 66.8 & 27.9 & 52 & 17.6 & 28.4 & 18.6 & 27.1 & 4 \\
\hline Shanghai & 2.5 & 0.1 & 181 & 4.4 & 32.9 & 78.4 & 51.1 & 24.3 \\
\hline Jiangsu & 5.6 & 8.5 & 567.4 & 14.5 & 396.8 & 56.1 & 49.6 & 16.9 \\
\hline Zhejiang & 0.4 & 0.6 & 315.9 & 12 & 310.1 & 37.6 & 31.5 & 13.5 \\
\hline Anhui & 4.2 & 23.1 & 122.4 & 10.4 & 91.8 & 23.2 & 22.9 & 5.9 \\
\hline Fujian & 4.3 & 2.1 & 228.3 & 9.1 & 168.5 & 27.8 & 23.4 & 9.8 \\
\hline Jiangxi & 4.5 & 5.8 & 141.8 & 9.3 & 90.4 & 17.3 & 20.3 & 4.3 \\
\hline Shandong & 1.6 & 57.4 & 403.2 & 23.1 & 160.3 & 57.1 & 49.4 & 14.2 \\
\hline
\end{tabular}

Annotation:

A: Agriculture, forestry, animal husbandry and fishery

$\mathrm{B}$ : The mining industry

C: Manufacturing

D: Electric heating gas and water production and supply industry

E: The construction industry

F: Wholesale and retail

G: Transportation, warehousing and postal services

$\mathrm{H}$ : Accommodation and catering

Use SPSS for system clustering, and get the following average link clustering table (part):

Table 2 Agglomeration Schedule

\begin{tabular}{|c|c|c|c|c|c|c|}
\hline \multicolumn{7}{|c|}{ Agglomeration Schedule } \\
\hline \multirow[b]{2}{*}{ Stage } & \multicolumn{2}{|c|}{ Cluster Combined } & \multirow[b]{2}{*}{ Coefficients } & \multicolumn{2}{|c|}{ Stage Cluster First Appears } & \multirow[b]{2}{*}{ Next Stage } \\
\hline & Cluster 1 & Cluster 2 & & Cluster 1 & Cluster 2 & \\
\hline 1 & 29 & 30 & .145 & 0 & 0 & 2 \\
\hline 2 & 26 & 29 & .408 & 0 & 1 & 6 \\
\hline 3 & 24 & 28 & .842 & 0 & 0 & 10 \\
\hline 4 & 14 & 25 & 1.233 & 0 & 0 & 7 \\
\hline 5 & 5 & 7 & 1.435 & 0 & 0 & 10 \\
\hline 6 & 21 & 26 & 1.488 & 0 & 2 & 21 \\
\hline 7 & 14 & 22 & 1.612 & 4 & 0 & 8 \\
\hline 8 & 12 & 14 & 2.093 & 0 & 7 & 12 \\
\hline 9 & 3 & 18 & 2.642 & 0 & 0 & 11 \\
\hline 10 & 5 & 24 & 2.724 & 5 & 3 & 14 \\
\hline 11 & 3 & 17 & 3.172 & 9 & 0 & 16 \\
\hline 12 & 12 & 13 & 3.371 & 8 & 0 & 14 \\
\hline 13 & 15 & 16 & 3.557 & 0 & 0 & 22 \\
\hline 14 & 5 & 12 & 4.478 & 10 & 12 & 20 \\
\hline 15 & 6 & 27 & 4.522 & 0 & 0 & 17 \\
\hline
\end{tabular}


The second and third columns of the table represent the class of aggregation, and the fourth column represents the aggregation coefficient, which is the value of distance measurement. The fourth and fifth columns represent the first occurrence of the clustering part of the two terms merged. Both Cluster1 and Cluster2 are 0, indicating the combination of two samples, and one of them is 0 , indicating the combination of sample and class. The sixth column indicates that the new classes generated by the corresponding steps will be merged with other samples or new classes in step 1.

Finally, the clustering process is illustrated in the form of pedigree chart:

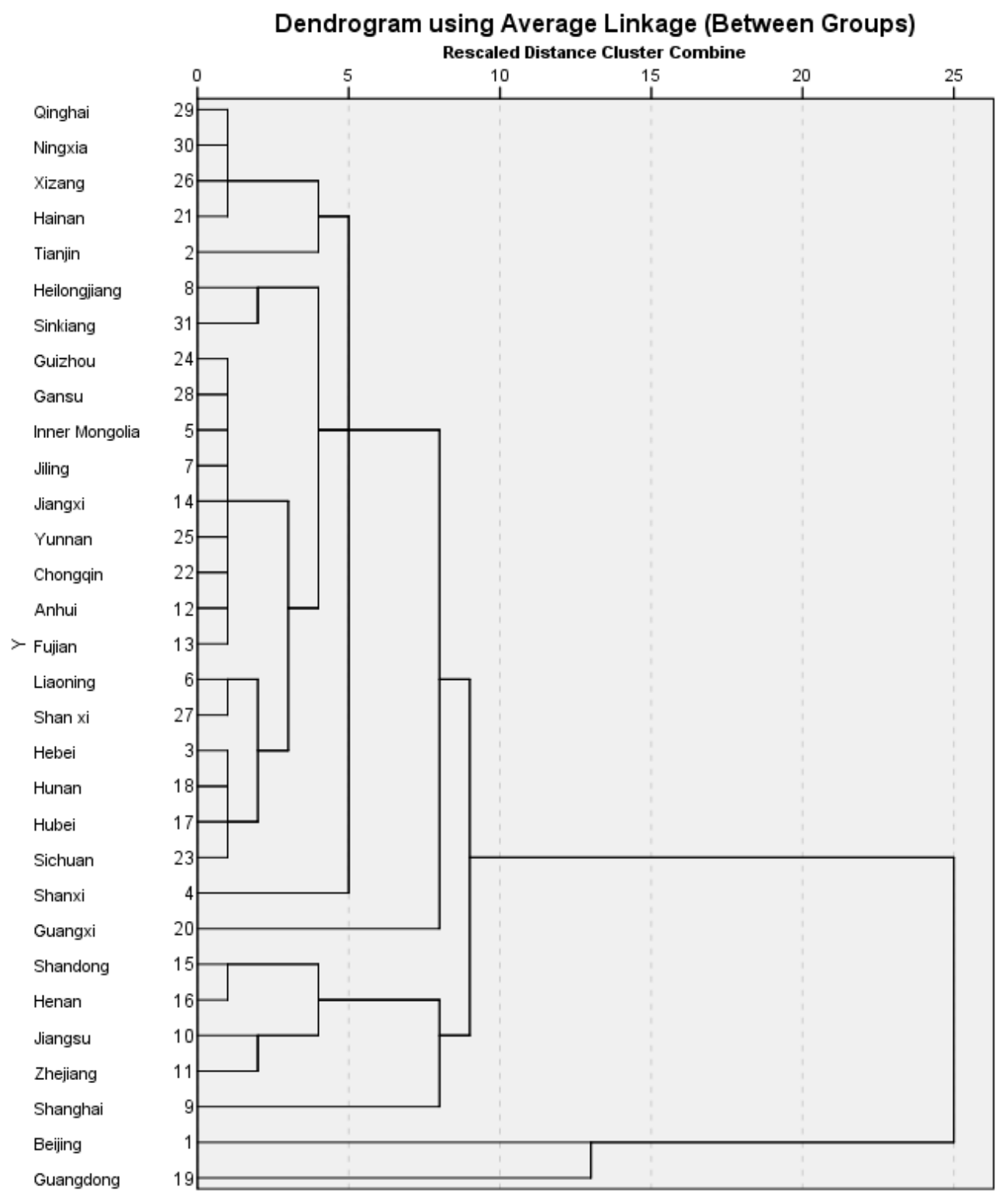

Fig 1 Pedigree chart

It can be seen from the pedigree chart that it is suitable to be divided into 4 categories. Guangdong was the first, Beijing the second, Shandong, Henan, Jiangsu, Zhejiang, Shanghai the third and the rest the fourth.. Beijing, as the capital, has a relatively large number of employees in the service and financial sectors, which is conducive to promoting economic development. Guangdong, by contrast, is both a coastal city and close to Hong Kong and macau, with a well-developed industry and far more manufacturing and construction jobs than any other province. 
Shandong, Zhejiang, Jiangsu and Shanghai are all coastcities, close to the yellow sea and East China Sea.

\section{Reasons and Suggestions}

\subsection{Cause analysts}

On December 26, 2016, 21st century economic research institute released the report of 21 comprehensive development level index 2016", which showed that the top 10 provinces were Beijing, zhejiang, Shanghai, guangdong, jiangsu, chongqing, hunan,fujian, sichuan, henan(hubei, shandong). Among them, hubei, shandong and henan are tied for 10th place. Except that hunan, hubei and henan are in the central part and chongqing and sichuan are in the west, the other seven are from the east.

It can be seen that most of the cities in the front are eastern ones, while most of the latter are western ones, and the central provinces and cities are in the middle, mainly because they have not formed their own characteristics or played their own advantages, and their geographical position has a great impact on the economic development level of each province.

Some of the provinces and cities with high level of urbanization and industrialization benefit from higher GDP and industrial output value. However, the provinces and cities without the development of front-end industries are mainly due to the lack of industrial development which is mainly caused by the lack of investment in fixed assets, especially in some large agricultural provinces, and the lack of investment in rural fixed assets. this has led not only to the inability of other industries to attract talent, but also to retain talent in the advantageous industries.

\subsection{Policy Suggestions}

The state should implement better and more preferential policies for backward provinces and cities, and strengthen reform measures for backward provinces and cities, especially for rural areas in western regions, to help them improve the environment for comprehensive economic development. We will strengthen support for industries with better development prospects in different cities and give play to their own characteristics.

The state should strengthen the administration of taxation, distribution and other aspects in developed provinces such as Beijing and Shanghai, and strengthen the central government's financial resources to increase the state's support for western provinces such as xinjiang and gansu as well as backward regions to achieve common development.

In view of the dominant industries in different cities, the dominant position should be highlighted, the influence should be enhanced to drive the development of other industries, the relatively backward industries should be reformed and innovated, and the competitiveness should be enhanced. For example, the financial industry in Beijing should strengthen investment and construction, while shanxi should focus on the mining industry.

Strengthening investment in key industries is conducive to retaining talents and attracting applicants.

\section{References}

[1] Christos A. Makridis, Michael Ohlrogge. Validating RefUSA micro-data with the Longitudinal Employer-Household Dynamics Data [J]. Economics Letters, 2017.

[2] Jamaliah. The Effect of Investment to Value Added Production, Employment Absorption, Productivity, and Employees' Economic Welfare in Manufacturing Industry Sector in West Kalimantan Province [J]. Procedia - Social and Behavioral Sciences, 2016,219. 
[3] Bin Fang,Qiang Ye,Rob Law. Effect of sharing economy on tourism industry employment [J]. Annals of Tourism Research, 2016, 57.

[4] Ramya Naraharisetti, Marcia C. Castro. Factors associated with persons with disability employment in India: a cross-sectional study [J]. BMC Public Health, 2016, 16(1).

[5] Turkstat $(1985,1990,1998)$ Input-Output Tables. Turkish Institution of Statistics, Ankara

[6] Rubart J (2007) The employment effects of technological change. Springer-Verlag, Berlin Heidelberg

[7] Peppi Saikku. Primary health care services in activation and employment [J]. International Journal of Integrated Care, 2010, 10(7).

[8] Gournellis Rossetos , Triantafillou Eugenia , Madianos Michael et al.. Diachronic trends of employment outcome of prevocational training in psychiatric rehabilitation [J]. Annals of General Psychiatry, 2010, 9(1).

[9] Catherine H. Stewart, Philip Berry, Dunja Przulj et al.. Cancer-related health behaviours of young people not in education, employment or training ('NEET'): a cross-sectional study[J]. BMC Cancer, 2017, 17(1).

[10] Gareth Hagger-Johnson, Ewan Carr, Emily Murray et al.. Association between midlife health behaviours and transitions out of employment from midlife to early old age: Whitehall II cohort study [J]. BMC Public Health, 2017, 17(1). 